\title{
INFLUENCE OF RESIDUAL LIGNIN CONTENT ON PHYSICAL AND MECHANICAL PROPERTIES OF KRAFT PULP / PP COMPOSITES
}

\author{
Majid Kiaei ${ }^{1, \diamond}$, Behzad Kord ${ }^{2}$, Ramin Vaysi ${ }^{1}$
}

\begin{abstract}
The effect of residual lignin content on the mechanical strength and water absorption of kraft pulp/ polypropylene composites was studied. To meet this objective, hornbeam wood chips were converted to kraft pulp at three different alkalinities $(15,20$, and 25\%) and three different cooking times (60, 90, and $120 \mathrm{~min})$. The residual lignin contents of these pulps were determined according to the TAPPI standard. Kraft pulp was mixed with polypropylene (PP) at 50\% weight ratios. The amount of maleic anhydride (MAPP) coupling agent was fixed at 4 per hundred compounds (phc) for all formulations. The results indicated that the lignin residual content decreased with increasing cooking time and alkalinity in kraft pulp. Also, it was found that tensile strength, tensile modulus, flexural strength, and flexural modulus were increased by increasing the alkalinity and cooking time; however, the notched impact strength and water absorption decreased. Overall, decreasing the lignin content had a positive impact on the flexural and tensile properties and had a negative effect on the notched impact strength.
\end{abstract}

Keywords: Alkalinity, cooking time, residual lignin content, mechanical properties, water absorption.

\section{INTRODUCTION}

Wood-plastic composites (WPC) are a group of materials made from a combination of wood fiber (or flour) and a thermoplastic resin, together with varying amounts of additives. WPC popularity and expansion into residential markets and the construction industry, which includes siding, exterior decking, and railing material, is due to the product's perceived low maintenance and environmental performance (lifespan and no toxic chemicals) relative to wood (Smith and Wolcott 2005, Kord 2011). Also, the dimensional stability of these materials tends to be greater than that of traditional wood products because of the presence of plastic, thereby rendering them suitable for application in end uses where dimensional stability is a prerequisite requirement. On the other hand, incorporation of wood fibers into plastics improves the flexural and tensile properties of the resulting composite material relative to pure plastics (Kord 2011).

Among polymer composites, those based on polypropylene (PP) have attracted considerable interest because polypropylene is one of the most widely used and fastest growing classes of thermoplastics with low cost (Kord 2012). Also, PP has been used in conventional composites for a long time and shows good mechanical properties, even with low amounts of filler (Woodhams et al. 1984).

\footnotetext{
${ }^{1}$ Department of Wood and Paper Engineering, College of Agriculture and Natural Resources, Chaloos Branch, Islamic Azad University (IAU), Chaloos, Iran

${ }^{2}$ Assistant Professor, Department of Paper and Packaging Technology, Faculty of Chemistry and Petrochemical Engineering, Standard Research Institute (SRI), Karaj, Iran

^ Corresponding author: mjd_kia59@yahoo.com

Received: 25.07.2013 Accepted: 01.02. 2014
} 
Lignin is widely distributed throughout the cell walls of wood, but it is highly deposited in the middle lamella region and its typically present at $20-30 \%$ in wood (Feist and Hon 1984). Lignin is a branched heterogeneous aromatic polymer formed of phenylpropane units linked together primarily by $\beta-\mathrm{O}-4$ arylether linkages (50 to $60 \%$ of all linkages). Lignin is characterized by the presence of different functional groups, such as phenolics, methoxyls, aliphatic alcohols, aldehydes, ketones, and ethers (Zakis 1994). Sinapyl alcohol, coniferyl alcohol, and p-coumaryl alcohol are involved in the biosynthesis of hardwood lignin (Mattias 2000, Bonawitz 2010). In wood, there is a chemical connection between lignin and hemicelluloses. Because the lignin structure is both polar and nonpolar, lignin can cause more compatibility between polymer and wood flour in WPC materials. Lignocellulosic materials are polar by nature, whereas polymers are nonpolar by nature. Thus, a good connection between these two phases does not accrue in normal conditions (Behrooz et al. 2010).

Lignin is one of the major components of all natural fibers has poor reinforcing effects in composites when used alone. The removal of lignin from cellulosic fibers could help to improve the mechanical properties of natural fiber-plastic composites in two ways: by increasing the stronger and stiffer cellulose content at a given fiber fraction, and by improving the adhesion between the two phases of the composites through the elimination of the less chemically reactive lignin component (Karimi et al. 2006). Rozman et al. (2000) prepared acid lignin base using the Klason method as a coupling agent in coconut fiber-polypropylene composites. The results showed that the composite materials had better physical and mechanical properties than the control samples. Karimi et al. (2006) reported that delignified fibers improvement the tensile strength and tensile modulus, whereas the hardness of composites was unaffected by delignification. Delignified fibers also exhibited better water absorption resistance. Notched impact strength was higher for delignified fiber composites, but it was reduced at higher delignification levels. Beg and Pickering (2007) reported that residual lignin content decreased with progressive washing and bleaching. Fiber with higher amounts of residual lignin content led to composites with lower tensile and impact strengths and increased degradability when subjected to accelerated weathering testing.

The aim of this study was to investigate the influence of pulping condition variables such as the alkalinity and cooking time on the physical and mechanical properties of kraft pulp/polypropylene composites.

\section{MATERIALS AND METHODS}

\section{Materials}

Several discs from hornbeam (Carpinus betulus) logs were obtained from the Sari region (Mazandaran Province, Iran) and then converted into chips. The chips were $20 \mathrm{~mm}$ in length and $4 \mathrm{~mm}$ thick, on average. The Kraft pulp of hornbeam wood was used as a filler material. The polymer matrix used in this study, PP, was supplied by Arak petrochemical industries (Arak, Iran) and had a melt flow index of $8 \mathrm{~g} / 10 \mathrm{~min}$ and a density of $920 \mathrm{~kg} / \mathrm{m}^{3}$. Composite profiles consisted of PP and Kraft pulp at $50 \%$ weight ratios. Polypropylene grafted with maleic anhydride (MAPP) with a melt flow index of $64 \mathrm{~g} / 10 \mathrm{~min}$ as the coupling agent was acquired from Solvay Company, Belgium. The amount of coupling agent was fixed at 4 per hundred compounds (phc) for all formulations. The chemical materials used for cooking liquor include of $\mathrm{Na} 2 \mathrm{~S}$ and $\mathrm{NaOH}$ were supplied by Merck Co. (Frankfurt, Germany).

\section{Methods \\ Kraft pulping}

Having prepared wood chips of certain dimensions, the moisture content of the samples was determined. The variable factors were alkalinity $(15,20$, and $25 \%)$ and cooking time $(60,90$, and $120 \mathrm{~min})$, while the constant factors were cooking temperature $\left(170^{\circ} \mathrm{C}\right)$, sulfidity $(25 \%)$, Pressure $7 \times 10^{5}$ Pascal $(7 \mathrm{bar})$ and the ratio of cooking liquor to dry weight of samples ( 7 to 1$)$. At the end of the pulping process, the complete dry weight of the pulp sample was calculated after rinsing, drying, and calculating the moisture content. The Kappa number of the pulp was found based on the T236 om-99 standard. The results of cooking tests on the Kraft process demonstrated that three treatments, namely (a) 15\% alkalinity and 60-min cooking time; (b) 15\% 
alkalinity and 90-min cooking time; and (c) 15\% alkalinity and 120-min cooking time, were not and strong enough. Therefore, these treatments were not sufficient to transform the wood chips into kraft pulp. Thus, the T222 om-02 standard was used to determine the lignin content of these three treatments. The fibers obtained from alkalinities of 15,20 , and $25 \%$ were converted to flour at different times using a ball mill. The results of experiments on the kraft pulp (Figure 1) showed that by increasing the cooking time and the alkalinity, the Kappa number value was decreased. This can be attributed to the greater concentration of chemicals and thus higher rate of lignin-removal reactions. Meanwhile, the same trend was seen for the cooking time and may be due to the increased delignification at longer cooking times (Vaziri et al. 2009).

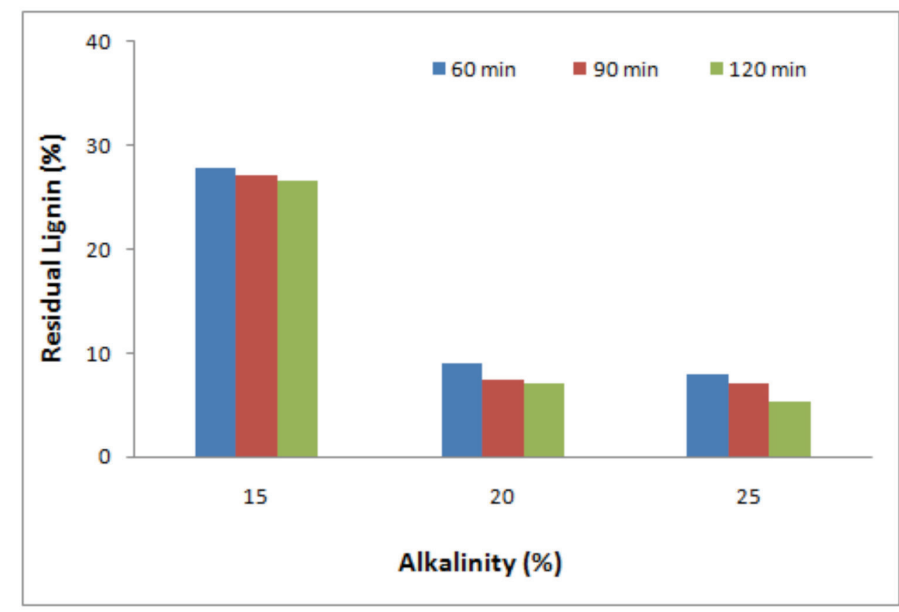

Figure 1. The effects of alkalinity and cooking time on the residual lignin in kraft pulp.

\section{Processing of the composites}

Before sample preparation, the kraft pulp was dried in an oven at $70 \pm 2{ }^{\circ} \mathrm{C}$ until it reached a constant weight. The mass ratio of kraft pulp to polypropylene (PP) was controlled at 50:50\% by weight for all blends. The amount of coupling agent was fixed at 4 per hundred compounds (phc) for all formulations. The mixing was carried out with a co-rotating twin-screw extruder (Model T20, 1990, Dr. Collin GmbH, Germany), with its barrel temperature ranging from 140 to $160^{\circ} \mathrm{C}$ at six zones, from feeding zone to the die zone, at a screw speed of $110 \mathrm{rpm}$. First, the polypropylene was fed to the mixing chamber, and after 2 minutes the PP was melted. Then, the coupling agent was added, the melting process of MAPP took in 3 minutes. At the fifth minute, the kraft pulp was fed into the chamber, and the total mixing time was $13 \mathrm{~min}$. The compounded materials were then ground using a pilot-scale grinder (WIESER, WGLS 200/200 Model). The resulting granules were dried at $105^{\circ} \mathrm{C}$ for $4 \mathrm{~h}$. Test specimens were injection molded according to ASTM D3641standard by an injection molder at a molding temperature of $185^{\circ} \mathrm{C}$ and injection pressure of $3 \mathrm{MPa}$ (Eman machine, Aslanian Co, Iran). Finally, specimens were conditioned at a temperature of $23{ }^{\circ} \mathrm{C}$ and relative humidity of $50 \%$ for at least $40 \mathrm{~h}$ prior to testing according to ASTM D 618.

\section{Mechanical properties}

The flexural and tensile tests were conducted according to ASTM D 790 and D 638, respectively, using an Instron machine (Model 1186, England); the tests were performed at crosshead speeds of $5 \mathrm{~mm} / \mathrm{min}$. A Zwick impact tester (Model 5102, Germany) was used for the Izod impact test. All samples were notched at the center of one longitudinal side according to ASTM D 256. 


\section{Physical properties}

Water absorption tests were carried out according to ASTM D 7031 specifications. Specimens with dimensions of $20 \times 20 \times 20 \mathrm{~mm}$ were cut for water uptake measurements. Five replicates were used for each sample type. To ensure the same moisture content for the specimens before each test, all the specimens were oven-dried at $75 \pm 2{ }^{\circ} \mathrm{C}$ for 48 hours to dry. The weights and thicknesses of dried specimens were measured to precisions of $0.001 \mathrm{~g}$ and $0.001 \mathrm{~mm}$. The specimens were then placed in distilled water and kept at room temperature for one month $(720 \mathrm{~h})$. For each measurement, specimens were removed from the water and the surface water was wiped off using blotting paper. The weights and thicknesses of the specimens were measured at different time intervals during the immersion. The measurements were terminated after the equilibrium thicknesses of the specimens were reached. The values of the water absorption in percentage were calculated using the following equation.

$$
W A(t)=\frac{W(t)-W_{0}}{W_{0}} \times 100
$$

where $W A(t)$ is the water absorption at time $t, W_{o}$ is the oven-dried weight, and $W(t)$ is the weight of a specimen at a given immersion time $t$.

\section{Statistical analysis}

The statistical analysis was conducted using Statistical Package for Social Science (SPSS, Version 16) in terms of one-way analysis of variance (ANOVA). The average values were compared and classified using the Duncan test at a $95 \%$ confidence level.

\section{RESULTS AND DISCUSSION}

Results of analysis of variance (ANOVA) indicated that the alkalinity, cooking time, and their interaction effects had a significant influence on the flexural strength, tensile strength, flexural modulus, tensile modulus, impact strength and water absorption of kraft pulp/polypropylene composites (Table 1).

Table 1. F-value (in analysis of variance) of the results of kraft pulp/polypropylene composites.

\begin{tabular}{lccc}
\hline \multicolumn{1}{c}{ Treatments } & alkalinity (A) & cooking time (B) & $\mathrm{A} \times \mathrm{B}$ \\
\hline Flexural strength & $1346,775^{* *}$ & $144,125^{* *}$ & $19,989^{* *}$ \\
Flexural modulus & $1550,014^{* *}$ & $183,951^{* *}$ & $3,670^{*}$ \\
Tensile strength & $673,432^{* *}$ & $87,635^{* *}$ & $5,362^{* *}$ \\
Tensile modulus & $559,877^{* *}$ & $65,427^{* *}$ & $3,261^{*}$ \\
Impact strength & $1187,814^{* *}$ & $226,185^{* *}$ & $26,270^{* *}$ \\
Water absorption & $438,103^{* *}$ & $509,48^{* *}$ & $192,6^{* *}$ \\
$* * *$ & & &
\end{tabular}




\section{Flexural and Tensile strength}

The influence of alkalinity and cooking time on the flexural strength, flexural modulus, tensile strength, and tensile modulus of kraft pulp/polypropylene composites is shown in Figure 2 to 5 . The tensile and flexural properties increased with increasing alkalinity and cooking time. The highest flexural and tensile strengths were observed for 25\% alkalinity and 120-min cooking time, whereas the lowest mechanical strength corresponded to $15 \%$ alkalinity and 60 -min cooking time (Figure 2, 3, 4, 5). An increase in mechanical strength meant that the stress was successfully transferred from the PP matrix to the fibers. Delignified fibers transferred the stress better than the original fibers. This phenomenon resulted in a higher flexural and tensile strength due to the improvement of the adhesion and the nature of the fiber/matrix interface. It was expected that cellulose would have a better chemical reaction with the coupling agent compared with lignin due to a higher concentration of hydroxyl groups. Therefore, the elimination of lignin from the fibers by higher alkalinity and cooking time improved interfacial bonding, which resulted in improvements in mechanical strength (Karimi et al. 2006, Beg and Pickering 2007).

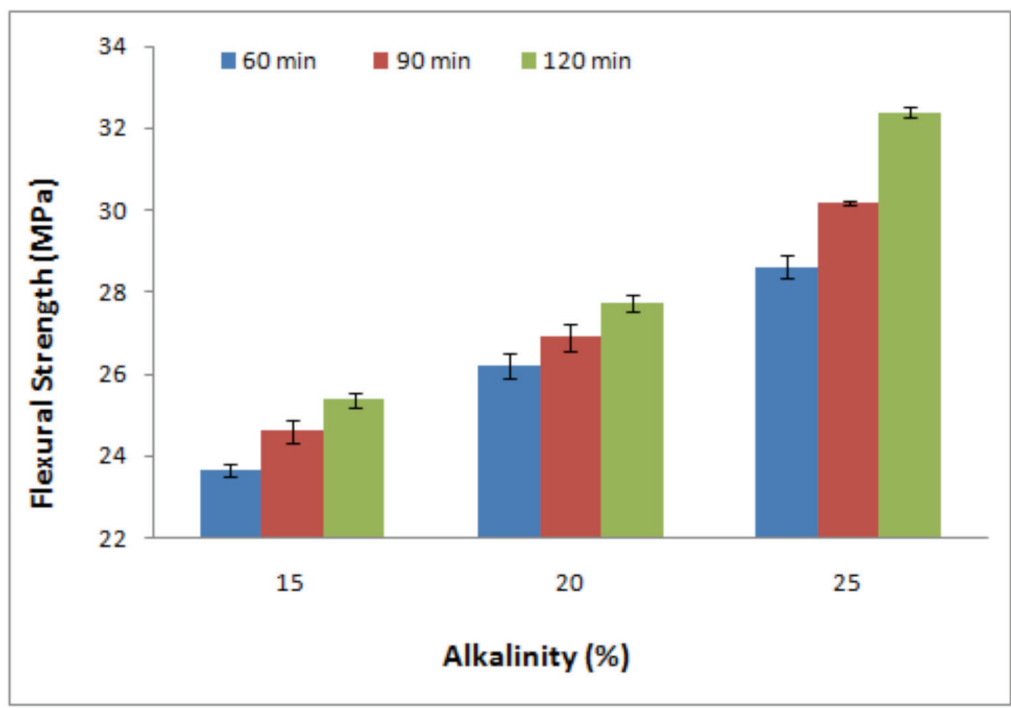

Figure 2. The effects of alkalinity and cooking time on the flexural strength of composites.

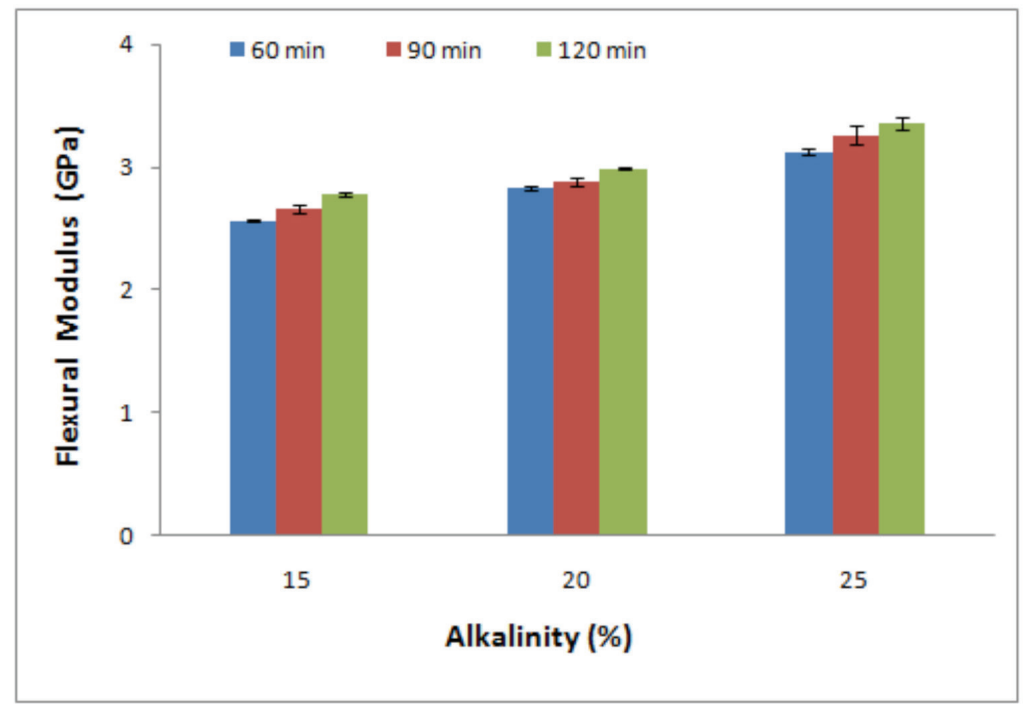

Figure 3. The effects of alkalinity and cooking time on the flexural modulus of composites. 


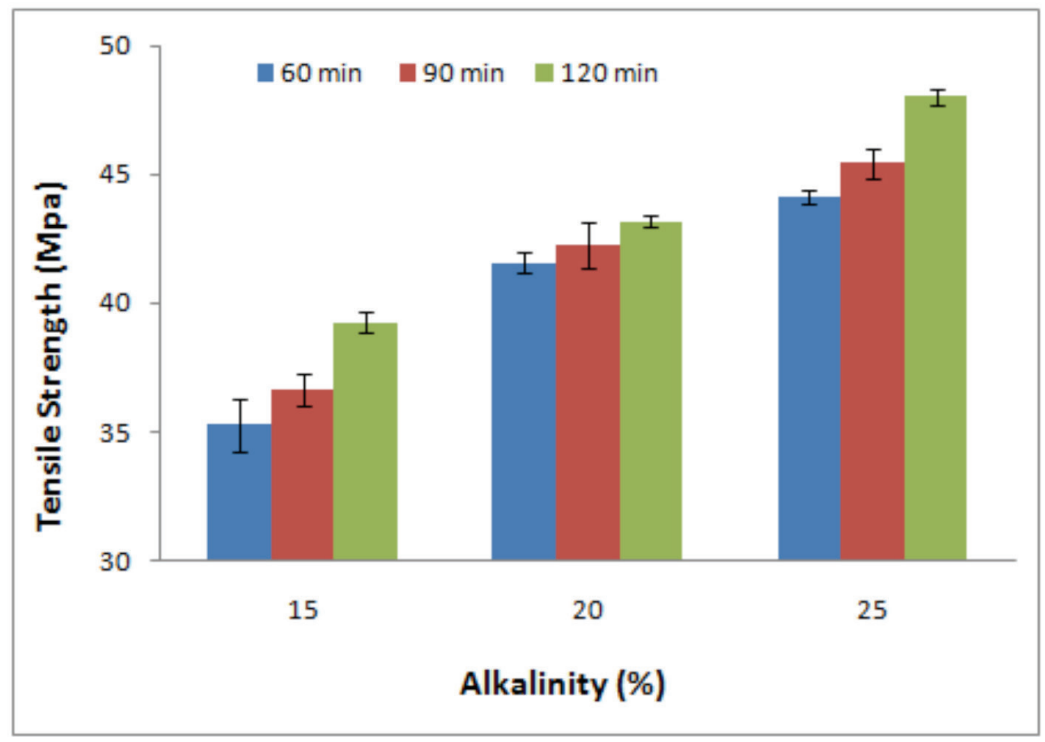

Figure 4. The effects of alkalinity and cooking time on the tensile strength of composites.

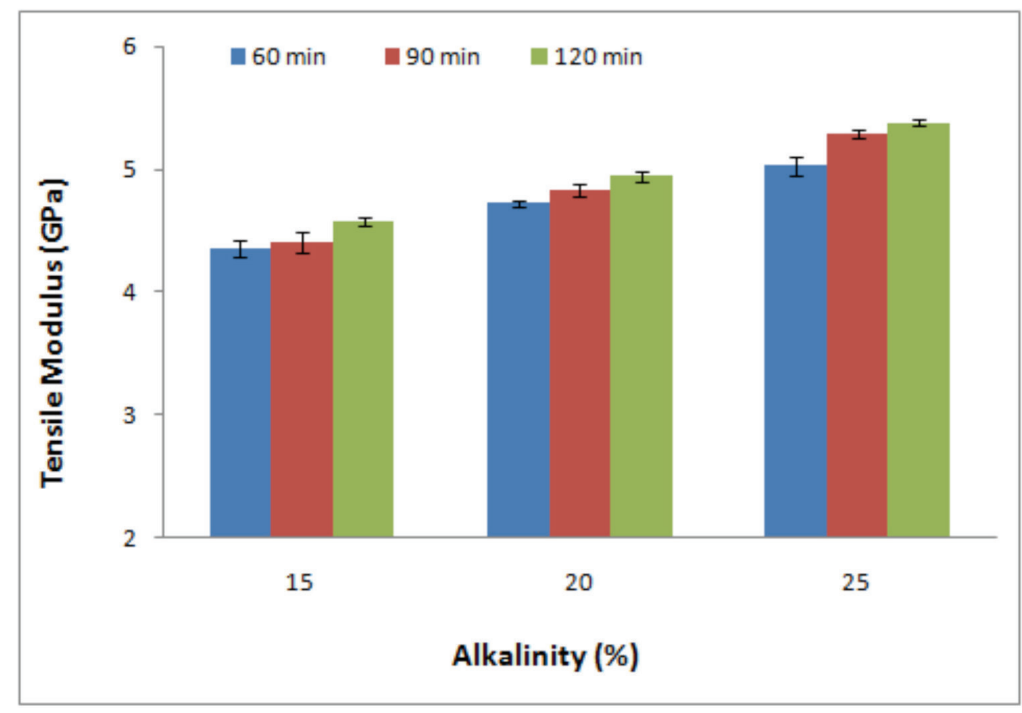

Figure 5. The effects of alkalinity and cooking time on the tensile modulus of composites.

\section{Impact Strength}

Figure 6 shows the effect of alkalinity and cooking time on the impact strength of Kraft pulp/polypropylene composites. This property decreased with increasing alkalinity and cooking time. The highest impact strength was observed for $15 \%$ alkalinity and 60-min cooking time; whereas the lowest impact strength corresponded to $25 \%$ alkalinity and 120 -min cooking time (Figure 6). However, notched impact strength decreased with increasing alkalinity and cooking time. Izod impact energy is the energy required for crack propagation. The size and dispersion of filler particles in the matrix can affect the properties of the composites. Small welldispersed particles generally lead to better properties. Small particles can block crack propagation and result in impact toughening. Particles with higher aspect ratios have high stresses at the fiber ends that can cause failure under impact (Beg and Pickering 2007). 


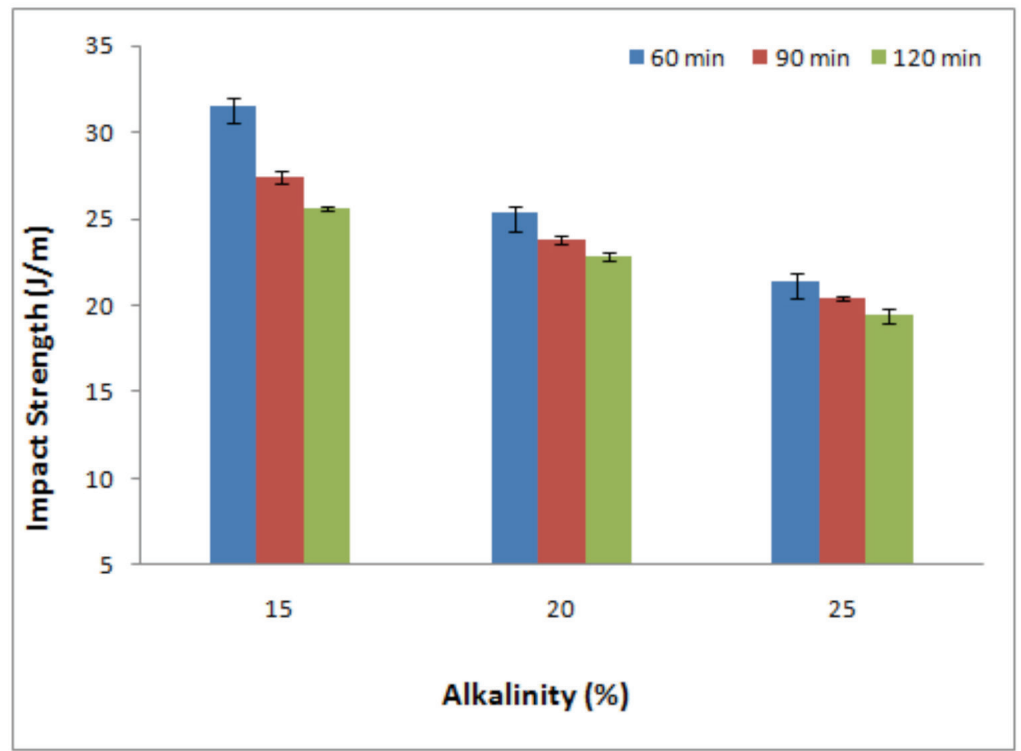

Figure 6. The effects of alkalinity and cooking time on the impact strength of composites.

\section{Water Absorption}

The influence of alkalinity and cooking time on the water absorption of Kraft pulp/polypropylene composites is shown in Figure 7. The water absorption decreased with increasing alkalinity and cooking time. The highest water absorption was observed for $15 \%$ alkalinity and 60 -min cooking time; whereas the lowest water absorption corresponded to $25 \%$ alkalinity and 120 -min cooking time (Figure 7). It is well known that bonding between the fiber surface and the matrix could have reduced available hydroxyl groups (Behrooz et al. 2009, 2010). On the other hand, due to a higher hygroscopicity of cellulose than lignin, the elimination of lignin led to a higher water absorption of fibers. It seems that the improvements in the compatibility between the two phases and bonding between fibers and matrix explained the lower water absorption in the delignified fibers (Karimi et al. 2006).

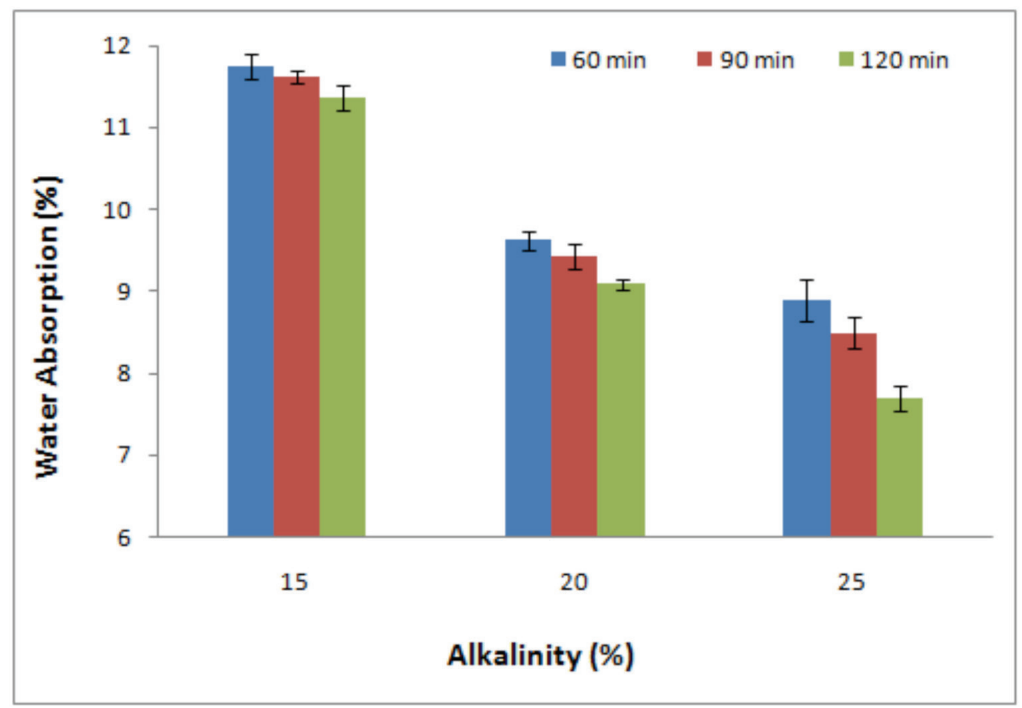

Figure 7. The effects of alkalinity and cooking time on the water absorption of composites. 


\section{CONCLUSION}

Increasing the cooking time from 60 to $120 \mathrm{~min}$ (decreasing residual lignin content) increased the values of modulus of elasticity, modulus of rupture, tensile strength, and tensile modulus by $7,8,8 ; 7,7$ and 5,6\%, respectively; the notched impact strength decreased by $13,3 \%$, and the amount of water absorption increased by $6.9 \%$.

Increasing the alkalinity from 15 to $25 \%$ (decreasing residual lignin content) increased the values of modulus of elasticity, modulus of rupture, tensile strength, and tensile modulus by 21,$7 ; 19,6 ; 23,6$ and $6,17 \%$, respectively; the notched impact strength decreased by $27,5 \%$ and the amount of water absorption increased by $27,8 \%$.

\section{REFERENCES}

American Society for Testing and Materials. ASTM. 2012. Standard Practice for Injection Molding Test Specimens of Thermoplastic Molding and Extrusion Materials. ASTM D3641-12. Annual Book of ASTM Standards. Philadelphia.

American Society for Testing and Materials. ASTM. 2013. Standard Practice for Conditioning Plastics for Testing. ASTM D618-13. Annual Book of ASTM Standards. Philadelphia.

American Society for Testing and Materials. ASTM. 2010. Standard Test Methods for Flexural Properties of Unreinforced and Reinforced Plastics and Electrical Insulating Materials. ASTM D790-10. Annual Book of ASTM Standards. Philadelphia.

American Society for Testing and Materials. ASTM. 2010. Standard Test Method for Tensile Properties of Plastics. ASTM D638-10. Annual Book of ASTM Standards. Philadelphia.

American Society for Testing and Materials. 2010. Standard Test Methods for Determining the Izod Pendulum Impact Resistance of Plastics. Annual Book of ASTM Standards. Philadelphia. ASTM D256-10.

American Society for Testing and Materials. 2011. Standard Guide for Evaluating Mechanical and Physical Properties of Wood-Plastic Composite Products. Annual Book of ASTM Standards. Philadelphia. ASTM D7031-11.

Beg, M.D.; Pickering, K.L. 2007. The effects of residual lignin content on wood fibre reinforced polypropylene composites. Advance Materials Research 29-30: 323-326.

Behrooz, R.; Kordkheili, H.Y.; Najafi, S. K. 2010. Effects of lignin method on physical and mechanical properties of wood flour-polypropylene composites. Iranian Journal of Wood and Paper Industries 1(2): 103-113.

Behrooz, R.; Kordkheili, H.Y.; Jalilvand, M. 2009. Using wastes of OCC paper recycling mills. Proceedings of $11^{\text {th }}$ International Conference on Environmental Science and Technology. Greece, 3-5 September.

Bonawitz, N. D. 2010. The genetics of lignin biosynthesis: Connecting genotype to phenotype. Annual Review of Genetics 44(1): 337-363.

Chanda, M.; Roy, S. K. 1998. Plastics Technology Handbook. $3^{\text {rd }}$ Ed., Marcel Dekker, New York. 
Feist, W.C.; Hon, D. N.S. 1984. Chemistry of weathering and protection. In: The Chemistry of Solid Wood. R. M. Rowell (ed.), Advances in Chemistry Series No. 207, American Chemical Society, Washington, DC.

Karimi, A.; Nazari, S.; Ghasemi, I.; Tajvidi, M.; Ebrahimi, G. 2006. Effect of the delignification of wood fibers on the mechanical properties of wood fiber-polypropylene composites. Journal of Applied Polymer Science 102(5): 4759-4763.

Kord, B. 2011. Nanofiller reinforcement effects on the thermal, dynamic mechanical, and morphological behavior of HDPE rice husk flour composites. BioResources 6(2): 1351-1358.

Kord, B. 2012. Effects of compatibilizer and naolayered silicate on physical and mechanical properties of PP/bagasse composites. Turk J Agric For 36(4): 510-517.

Mattias, J. 2000. Formation of chromophores and leuco-chromophores during manufacturing of mechanical pulp. Thesis submitted to Division of Wood Chemistry, Department of Pulp and Paper Chemistry and Technology, Royal Institute of Technology, Stockholm, Sweden.

Rozman, H.D.; Tan, K. W.; Kumar, R.N.; Abubakar, A.; Ishak, M.; Ismail, H. 2000. The effect of lignin as a compatibilizer on the physical properties of coconut fiber polypropylene composites. European Polymer Journal 36(7): 1483-1494.

Smith, P. M.; Wolcott, M. P. 2005. Wood-plastic composites emerging products and markets. In: Proc. $8^{\text {th }}$ Int. Conf. Wood Fiber-Plastic Composites. Madison, WI, May 23-25.

TAPPI (Technical Association of the Pulp and Paper Industry). 1994. Tappi Test Methods 1994. Tappi press, Atlanta.

Vaziri, V.; Hosseini, S. Z.; Dehghani, M. R. 2009. Effect of altitude on fiber characteristics, chemical composition and kraft yield pulp of Brutian pine (Pinus brutia). Journal of Wood and Forest Science and Technology 16(1): 1-13.

Woodhams, R.T.; Thomas, G.; Rodgers, D.K. 1984. Wood fibers as reinforcing fillers for polyolefins. Journal of Polymer Engineering Science 24(15): 1166-1171.

Zakis, G. F. 1994. Functional Analysis of Lignins and Their Derivatives. TAPPI Press, Atlanta, GA. 